\title{
O reencontro com a identidade de gênero: contribuições da visão sistêmica novo-paradigmática e do psicodrama infantil
}

\author{
The gender identity re-encounter: infant psychodrama \\ and new systemic view contributions
}

\author{
Maria Ivone Marchi COSTA \\ Maria Regina Corrêa Lopes VANIN²
}

\begin{abstract}
Resumo
Este estudo objetiva relatar os pontos principais do processo psicoterapêutico de um menino de dois anos e oito meses que apresentava transtorno de identidade de gênero, ou seja, sentia-se pertencente ao gênero feminino e desempenhava papéis a ele inerentes. O processo de base sistêmica novo-paradigmática e psicodramático foi permeado pelas modalidades individual, grupal e familiar, e se apoiou em técnicas psicodramáticas, recursos lúdicos e desenhos. A terapia desenvolveu-se por 24 meses e três encontros de follow up, e apresentou os seguintes resultados: ressignificação por parte da família quanto à relação e vínculo com a criança, o que possibilitou novas organizações interacionais e a construção de novos significados em torno da dinâmica familiar, permitindo que o menino também ressignificasse a sua importância e o seu lugar nessa família. Assim, diferenciou-se emocionalmente de sua irmã, aceitou sua identidade masculina, com conseqüente desempenho de papéis sociais a ela vinculados, manifestando mais segurança e autoria de vida.
\end{abstract}

Palavras-chave: identidade de gênero; psicodrama infantil; sistêmica.

\begin{abstract}
The purpose of this paper is to report the main points of the psychotherapeutic process of patient who was a 2-year-and-8-months-oldboy, who presented gender identity disfunction, i.e., the patient used to play a female role. In accordance with the psychodrama and the new paradigmatic approaches, the process was composed by individual, group and family modalities, with the psychodrama techniques, games resources and drawings support. The process has taken twenty-four month, followed by three follow-ups sessions. The process results were: the child's relationship and bonding re-meaning by family and the patient, new interactive organizations and new family dynamic meanings. As a consequence, the patient could elaborate the emotional differentiation from his sister, accepting his male identity that allowed his social roles performance.
\end{abstract}

Key words: gender identity; child psychodrama; systemic.

O presente estudo objetiva relatar os pontos principais do processo psicoterapêutico de um menino de dois anos e oito meses de idade, chamado aqui pelo nome fictício de Bruno, que apresentava comprometimento no desenvolvimento normal de sua identidade de gênero, caracterizado, de acordo

$\boldsymbol{\nabla} \mathbf{v} \boldsymbol{v}$

1 Departamento de Psicologia, Universidade do Sagrado Coração. Rua Irmã Arminda, 1-50, 13040-041, Bauru, SP, Brasil. Correspondência para/Correspondence to: M.I.M. COSTA.E-mail: <marchicosta@travelnet.com.br>.

2 Instituto Bauruense de Psicodrama. Bauru, SP, Brasil. 
com o CID 10, como transtorno de identidade de gênero.

O termo identidade de gênero foi criado pelo médico e psicanalista norte-americano Robert Stoller, em 1964, e refere-se à sensação da pessoa de pertencer ao gênero masculino ou feminino. De acordo com o CID 10 (Organização Mundial da Saúde, 1993), quando há alteração de identidade de gênero, as manifestações ocorrem, usualmente, na primeira infância (e sempre bem antes da puberdade), caracterizando-se por uma angústia persistente e intensa com relação ao sexo designado, juntamente com um desejo de ser (ou insistência de que é) do outro sexo. Há uma preocupação persistente com a vestimenta e/ou atividades do sexo oposto e/ou repúdio pelo próprio sexo (Grúnspun, 1999).

Costa (1994), psiquiatra e psicoterapeuta especialista em sexualidade humana, afirma que não se conhece totalmente como se dá o desenvolvimento da identidade de gênero e as causas de suas alterações. Entretanto, mesmo diante do desconhecimento das causas, a conduta da terapeuta não se fechou em determinismos e passou a investir no processo psicoterápico do menino Bruno, bem como em sua rede social, apostando, assim, nas correntes psicológicas que não subestimam as predisposições biológicas e acreditam também na força do ambiente e na forma como as experiências são significadas.

O processo psicoterápico teve por base teórica e técnica o pensamento sistêmico novo-paradigmático, representado pelo construcionismo social, pela abordagem narrativa ${ }^{3}$ e pelo psicodrama infantil.

A concepção sistêmica novo-paradigmática traz implícita uma postura construtivista e construcionista social da realidade, que descreve que a construção do conhecimento psicológico pertence ao domínio do intersubjetivo, no qual os significados são construídos nos espaços comuns de pessoas em relação. Nessa visão construcionista, a abordagem narrativa afirma que os conceitos psicológicos, como quaisquer outros, são construções sociais úteis, e não processos intrínsecos da mente, não devendo, pois, serem reificados como se fizessem referências a fatos de uma realidade externa e preexistente. Centra o processo nas narrativas socialmente construídas, incluindo o contexto cultural dessas famílias. Considera que as pessoas vivem suas vidas através de histórias, as histórias que organizam e dão sentido à experiência e que os problemas existem na linguagem, sendo capturados nas histórias dominantes, co-autorias nas comunidades lingüísticas das pessoas.

O terapeuta sistêmico novo-paradigmático trabalha com uma visão do todo, reconhecendo e focalizando as relações recursivas existentes não apenas no sistema familiar, como também no sistema terapêutico, em que ele próprio se inclui. Amplia o foco do sistema para o ecossistema, ou do sistema familiar para sistemas mais amplos do que a família, procurando mobilizar os recursos derivados dos vínculos que constituem as redes sociais (Vasconcellos, 2004a e b). Reconhece também a auto-organização e autonomia do sistema, com o qual não pode ter uma interação instrutiva e cuja evolução não pode prever nem controlar, mas pela qual é co-responsável.

O profissional une-se ao sistema com o qual trabalha na busca da construção conjunta de alternativas e soluções, utilizando conversações que evidenciem os sistemas de significados - as narrativas sobre o problema e as definições que esse recebeu. Enfim, trabalha com as pessoas que estão participando da conversação, oferecendo suas narrativas sobre o problema.

O pensamento sistêmico novo-paradigmático coloca por terra o dualismo entre sujeito e objeto; portanto, não tem como sustentar, também no contexto terapêutico, que o terapeuta detém um saber de especialista que transforma o cliente e seus problemas em seu "objeto" de conhecimento. O terapeuta não tem qualquer acesso privilegiado às pretensas verdades da vida das pessoas e seus dilemas, necessitando ser informado por elas. "Isto não significa que não sabemos nada, mas que estamos aquém do conhecimento absoluto" (Anderson, 1997, p.137).

Assim, não há como um terapeuta se colocar como um expert em "como os clientes devem viver suas vidas", ou saber de antemão qual a pergunta correta a fazer, qual a melhor narrativa a ser desenvolvida ou os conteúdos específicos a serem abordados. Da mesma

$176{ }^{3}$ No transcorrer deste estudo, esse referencial teórico será mencionado como visão ou concepção sistêmica novo-paradigmática. 
forma, caem também por terra as típicas perguntas avaliadoras, cunhadas do desejo do terapeuta de verificar as suas verdades, em vez de deixar se informar pelas realidades do cliente. Isso implica que, embora buscando a compreensão, é importante evitar elaborar conceitos muito rapidamente e colocar em dúvida o que já se parece saber, as generalidades, e evitar os julgamentos (Grandesso 2000b).

Segundo Freedman e Combs (1996), deve-se ouvir com base na perspectiva do cliente, procurando compreender, valendo-se de sua linguagem e dos seus significados. Contudo, de acordo com Grandesso (2000b), a principal característica da escuta do terapeuta é ser desconstrutiva, já que favorece a abertura para a construção de novas narrativas, embasadas em episódios da vida dos clientes ainda não historiados.

A definição de um problema é uma posição assumida dentro de um contexto conversacional, de uma determinada cultura, em que tal significado (o de ser um problema) é narrativamente construído, configurando-se, portanto, uma realidade social. Para que seja um problema, alguém deve defini-lo como tal, ou seja, não se pode falar em problemas independentemente do observador que os define. Nesse sentido, a definição em questão não pode prescindir da resposta às questões "para quem e por que é um problema"? Mais do que isso, não pode deixar de incluir como aspecto principal a narrativa dos que sofrem as influências desse problema (White \& Epston, 1990). Segundo Grandesso (2000a), somente os envolvidos podem relatar as histórias das tramas relacionais, dos sofrimentos e das restrições tecidos com base nas experiências vividas desde seu surgimento. Somente os protagonistas da história podem descrever como têm sido afetados na sua vida, nos seus relacionamentos, nas visões sobre si mesmos e nas suas perspectivas de futuro.

A exploração do problema e o desenvolvimento de possibilidades mais libertadoras pertencem a um território compartilhado com os clientes. É um processo co-construído na sessão, em um processo colaborativo entre cliente (entende-se cliente também como referência ao casal ou mesmo à família) e psicoterapeuta, e consiste em traçar uma espécie de mapeamento das influências dos problemas na vida das pessoas. Trata-se, assim, de compreender a forma como cada membro percebe o problema, em que medida essa visão afeta os demais, considerando-se, além das subjetividades, também a trama relacional - seja ela nossos clientes individuais, casais ou famílias. Tal prática favorece a inclusão, na narrativa dominante sobre o problema, de cada um dos participantes da conversação e não somente do paciente identificado.

Tal abordagem não compactua com uma visão essencialista de problemas como patologias ou disfunções em relação a quaisquer pretensos parâmetros normativos. Isso implica a perda da utilidade das categorias diagnósticas nosológicas. Embora estejam tão incorporados em nossa linguagem, a ponto de parecerem descrever os sistemas em questão, os termos e as categorias diagnósticas, bem como suas atribuições topológicas, são distinções que fazemos na linguagem, como observadores, servindo a propósitos socialmente definidos. Pelo uso, tais termos e categorias acabam se tornando reificados. Não restam dúvidas de que sistemas diagnósticos servem para legitimar, dar confiança e preditibilidade tanto para o terapeuta como para os clientes. Contudo, tal prática lingüística "obscurece a complexidade, a singularidade e a riqueza dos eventos e pessoas envolvidas" (Anderson, 1997, p.76).

Se um terapeuta compartilha o enfoque em questão, procurará suspender suas pré-concepções sobre problemas e terapêuticas, buscando defini-los como realidades trabalháveis nas singularidades de cada contexto e nos limites das pessoas envolvidas em conversação ao seu redor. Para Anderson (1997), suspender as pré-concepções quer dizer deixá-las expostas à nossa frente e aos outros, ser consciente delas, observá-las e refletir sobre elas, duvidar, desafiar e mudá-las. Assim, a exploração do problema e o desenvolvimento de possibilidades mais libertadoras pertencem a um território compartilhado com os clientes.

As narrativas - estáveis, regressivas ou trágicas dos clientes que buscam a terapia, sejam eles indivíduos, casais ou famílias, se apresentam, geralmente, estruturadas monologicamente em torno de suas inquietações que, como palavras correndo em 
volta da própria cauda, restringem suas possibilidades de estar em diálogo e, assim, de assumir múltiplas perspectivas. Portanto, a possibilidade de reconstrução de significados para os acontecimentos da vida encontra-se fechada. Isso porque suas histórias apresentam uma certa rigidez temática e são fixadas em algum tipo de permanência dos significados, em detrimento dos contextos, de modo que acabam sendo histórias dominantes na organização das relações dessas pessoas no mundo (White \& Epston,1990).

Normalmente, nos primeiros encontros, as narrativas historiadas vêm carregadas de significados aprisionantes e sofrimentos, pois a capacidade de autoria normalmente está empobrecida, impedindo a visualização de alternativas. No transcorrer do processo dialógico, por meio de perguntas reflexivas, apoiadas ou não por recursos intermediários, as narrativas vão sendo ampliadas e alguns significados vão sendo desconstruídos, favorecendo, assim, possíveis ressignificações e, por conseqüência, alívio de sofrimentos.

O processo de Bruno apoiou-se também no psicodrama, cujo núcleo teórico fundamental é a criatividade e a espontaneidade. Tem como foco central "o homem em relação", visto como ser social porque nasce em sociedade e precisa do outro para reconhecer-se como tal, desenvolver sua singularidade e, assim, poder sobreviver.

Segundo Bermúdez (1970), a matriz de identidade é o lugar (locus) onde o recém-nascido se insere desde o nascimento, relacionando-se com objetos e pessoas dentro de um determinado clima. No seu início, a matriz de identidade está ligada basicamente aos processos fisiológicos; posteriormente, e coincidindo com a evolução da criança, vincula-se aos processos psicológicos e sociais. A matriz de identidade, pois, provê a criança do alimento físico, psíquico e social. A ela cabe a fundamental tarefa de transmitir à criança, através dos papéis existentes, a herança cultural do grupo a que pertence e de prepará-la para sua posterior incorporação na sociedade. A criança, pois, aprende tais papéis através de um processo que évariável quanto ao tempo de duração. Tal processo tem como característica a coação, a coexistência e a coexperiência.
A terapia psicodramática infantil conta com uma forma específica de brincadeira: o teatro de faz-deconta. Na representação dramática, agindo "como se" ou "fazendo de conta que", a criança expressa o que atinge sua sensibilidade, o que dá prazer ou desprazer e vontade ou medo de aprender. Revela o sentimento que o mundo tem para com ela ou o revê por intermédio de papéis imaginários que é capaz de reconhecer, imitar e interpretar. No contexto psicodra-mático, fora do clima de tensão que a vida real apresenta, a criança pode reviver as situações pelas quais passou a testar novas maneiras de reagir ou se comportar em ocasiões diversas (Bermúdez,1997).

Moreno (1975) utiliza o termo acting out, que tem sua origem no teatro, para designar o processo de concretização, em atos, dos pensamentos e das fantasias. A criança, por intermédio do acting out no cenário, através do lúdico, manifesta determinados aspectos de seu mundo interior e exterior. Nesse atuar terapêutico, a criança vai mostrando seu perfil psicológico, suas particularidades, suas características, as situações que Ihe são conflituais e sua maneira de encará-las. Esse atuar possibilita à criança desembaraçar-se dos personagens internos e assumir plenamente seu papel, possibilitando o insight.

Para Moreno (1975), esse é o fenômeno que dá o verdadeiro sentido (valor) terapêutico ao psicodrama. Através da ação dramática, o indivíduo torna-se inteiro, completando alguma etapa de seu processo de identidade.

A catarse de integração está incluída no processo terapêutico e constitui o ápice de um caminho, no qual, gradativamente, ocorre a integração sistemática dos vários conteúdos que vão sendo trabalhados e/ou vivenciados pela criança.

\section{Estudo de Caso}

Bruno, filho caçula de um casal de aproximadamente 32 anos, freqüentava a escola maternal. A mãe era professora universitária e profissional liberal bem-sucedida; o pai era bancário e havia perdido seu cargo de gerência e retornado a uma função inferior em termos hierárquicos; a irmã mais velha, de seis anos, reconhecida pelos familiares como bonita, extrovertida e líder, freqüentava a pré-escola e era uma importante fonte de admiração e imitação por parte de Bruno. 


\section{O que os pais apresentaram como problema}

Encaminhados por uma fonoaudióloga, a quem procuraram em razão de Bruno apresentar gagueira acentuada nos últimos dois meses, os pais marcaram uma entrevista, pois, segundo a profissional, o quadro sugeria uma investigação psicológica.

Os pais apresentavam-se preocupados e ansiosos por não saberem o que estava acontecendo com seu filho, que até dois meses antes falava de forma tão correta e brilhante que chamava a atenção de todos. Bruno não apresentava nenhum antecedente que justificasse qualquer problema de ordem física, até então, apresentava desenvolvimento biopsicosocial normal, de acordo com o que era esperado para sua idade.

\section{A ampliação da história de Bruno e do seu contexto sob a perspectiva dos pais}

A psicoterapeuta favoreceu, por meio da dialogicidade, ampliações das narrativas dos pais, buscando conhecer o significado que atribuíam à gagueira de Bruno. Foi hipotetizado que esse sintoma poderia estar sendo o denunciador de algum sofrimento psíquico que o filho poderia estar vivenciando. E que seria importante haver um desvelamento de conteúdo significativo, em um processo de co-construção colaborativa entre cliente (considera-se cliente Bruno e sua família) e terapeuta (Grandesso, 2000b).

Os pais levantaram a possibilidade de o filho estar compartilhando da ansiedade que estavam vivenciando, pela perda do posto de trabalho do pai, que, com isso, sofreu um decréscimo financeiro e de status, tornando-se ambos impacientes com os filhos, e especialmente com Bruno. Relataram também que o menino estava Ihes trazendo uma certa inquietação pela sua insistência em brincar com as bonecas da irmã, ocasionando momentos de tensão quando insistia nesse propósito apesar da negativa dos pais. Não aceitavam tal fato, pois não queriam ter um filho homossexual, e por isso não permitiam tais brincadeiras, escondiam as bonecas e tudo da irmã que chamasse a atenção de Bruno, como tiaras, pulseiras, batons etc., alegando que eram coisas de meninas e que ele não era mulherzinha. Nesse sentido, a mãe complementou, afirmando que sentia uma certa culpa quanto ao comportamento do filho, já que na gestação de Bruno queria uma menina, pois idealizava a repetição do que havia sido e continuava sendo a primeira filha. Descrevia a menina como linda, inteligente, extrovertida, a alegria dos pais e dos avós, já que se tratava da primeira neta. Com o nascimento de Bruno, inicialmente, ela resistiu em aceitar o menino, algo que se intensificou com o fato de Bruno ter nascido magrinho, chorão, doentinho, orelha de abano e também pelo pós-parto ter-lhe sido muito difícil e dolorido.

A psicoterapeuta ampliou as narrativas dos pais, possibilitando a construção de novos significados em torno do comportamento do filho ao considerar que, de acordo com o desenvolvimento infantil, na idade de Bruno a criança normalmente ainda não aprendeu claramente a delimitação dos papéis sociais de gênero. Compartilhou a preocupação em relação à excessiva valorização desse fato, destacando que isso poderia possibilitar o desenvolvimento de uma maior fixação e também repercutir no desenvolvimento emocional de Bruno, já que as censuras eram freqüentemente acompanhadas de rotulações que o desqualificavam.

O passo seguinte foi conhecer Bruno e suas percepções para compreender o significado de sua gagueira sob o seu ponto de vista. Combinou-se que, após algumas sessões, haveria um novo encontro e que a direção do processo de Bruno seria definida em conjunto.

\section{O processo psicoterapêutico}

A psicoterapia de Bruno teve como apoio encontros alternados com o casal, com todos os membros familiares, somente com Bruno e o pai, Bruno e a mãe, Bruno e a irmã, e com os avós maternos.

Os encontros foram permeados por recursos intermediários técnicos (técnicas psicodramáticas, recursos lúdicos, desenhos etc.) cujo objetivo era favorecer a expressão, conversação dialógica e ampliar as narrativas em torno das vivências de Bruno e seus familiares e favorecer a emergência do não-dito.

Esse tipo de recurso também se estendeu por ocasião dos encontros familiares, já que eram necessários recursos intermediários lúdicos, especialmente

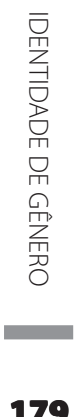

179 
quando a criança estava presente no contexto terapêutico, favorecendo a emergência das narrativas da família em torno de sua história.

Grandesso (2000a), terapeuta familiar de base sistêmica novo-paradigmática, considera fundamental nos encontros familiares com crianças o envolvimento dos pais como colaboradores ativos do processo. Mediante a sessão lúdica, torna-se possível conversar a respeito da família, porque o lúdico, terreno acessível a todos por ser uma linguagem universal, vem ao encontro desse intento.

\section{Período inicial}

\section{O encontro com Bruno}

Bruno chegou à sessão trazendo consigo uma boneca, momento em que a terapeuta percebeu que os pais haviam ressignificado essa questão e que a parceria já se iniciara. Ele mostrou a boneca, que foi elogiada, mas não supervalorizada. Observou-se que a gagueira realmente era intensa, às vezes havia dificuldade em compreender o que Bruno dizia; também falava de forma mais infantilizada do que o esperado para sua idade e apresentava trejeitos femininos.

Bruno se mostrou amistoso e interessado pelos brinquedos da sala. Após o rapport, deixou a boneca e começou a brincar de casinha e com os bonecos, desempenhando papéis femininos: ora era a mamãe ora a filhinha. Observou-se que não trouxe para a brincadeira nem o pai nem a si próprio como menino. Quando Ihe foi perguntado se havia mais alguém na casa, a resposta foi negativa.

Nas sessões subseqüentes, o desempenho exclusivo de papéis femininos se manteve por intermédio de personagens como fadas e princesas. Nem o menino nem o pai ou qualquer outra pessoa do gênero masculino apareceu nas cenas psicodramáticas que se desenvolveram no transcorrer das sessões. Durante as dramatizações, a terapeuta lançou mão da técnica interpolação de resistência (técnica que pode ser usada pelos terapeutas para modificação da situação dramática ou então para retomar algum material que não tenha sido elaborado em situações anteriores), solicitando a presença de um personagem do gênero masculino, visto que era pertinente ao contexto que estava sendo dramatizado (rainhas e princesas), a presença de um príncipe ou rei para ajudar, pois as personagens estavam em apuros. Houve rejeição, dizendo que o príncipe havia morrido e o rei mudado para bem longe.

Os papéis psicodramáticos expressam a dimensão psicológica do "eu": são todos aqueles papéis que surgem da atividade criadora do indivíduo. Envolvem, inclusive, os papéis preexistentes, como aqueles da fantasia, já que o que os caracteriza é o matiz criativo impresso neles e não o seu caráter em si (Moreno, 1975).

Após cinco sessões, a gagueira havia terminado totalmente. A questão da identidade de gênero, no entanto, se evidenciava. Ficou claro que Bruno não apenas desempenhava papéis femininos, mas também se sentia uma menina, e angustiava-se quando forçado a desempenhar papéis do gênero masculino. Ficava caracterizado, assim, de acordo com a literatura, o transtorno de identidade de gênero.

\section{As percepções da psicoterapeuta}

A gagueira, possivelmente, tenha sido uma forma de denunciar a ansiedade subjacente, decorrente das pressões ambientais. Os pais, agora mais confiantes e menos ansiosos por estarem sendo acompanhados por uma profissional, conseguiram lidar melhor com o comportamento feminino de Bruno. Com isso, minimizaram-se as pressões; o apoio do espaço terapêutico, onde Bruno podia expressar-se livremente sem que houvesse julgamentos, favoreceu para que ele se sentisse aceito, a ansiedade diminuiu e a gagueira se extinguiu.

O processo terapêutico, a partir de então, objetivou ampliar as narrativas da família e favorecer a emergência e a compreensão do não-dito, ou seja, o significado da necessidade de Bruno sentir-se e comportar-se como menina e rejeitar veementemente o menino e outras pessoas do gênero masculino de forma mais ampla, como, por exemplo, seu pai e outros membros da família extensa.

Bruno também se comunicava de forma mais infantilizada que o esperado para sua idade, imitando um bebê; comportava-se de forma insegura em 
algumas brincadeiras e recuava diante de alguns desafios, como receber uma bola lançada, brincadeira com espadas etc.

Além dos vínculos, fazia-se necessário possibilitar à família a construção de novos significados em torno de alguns aspectos interacionais, tais como posturas superprotetoras que complementavam a insegurança, e o sentimento de Bruno de não se sentir aceito como menino.

A flexibilização dos pais e a permissão, no espaço terapêutico, para expressar-se livremente por meio do lúdico, propiciaram a emergência de sua subjetividade. Bruno passou a comportar-se mais espontaneamente no desempenho de papéis femininos e a escolha de brinquedos e acessórios inerentes a eles se tornou freqüente. Suas inseguranças também foram sendo reveladas mais efetivamente diante dos desafios com que se deparava.

Nesse período, o investimento na parceria com a família foi intenso, e o pai foi incentivado a ser mais presente emocional e afetivamente junto ao filho, visando favorecer modelos masculinos. Vale ressaltar que, por ocasião da gagueira e logo em seguida da procura por serviços psicológicos, a mãe (talvez movida pela necessidade de reparação, decorrente da culpa que anteriormente relatou sentir) mobilizou-se mais intensamente em torno do filho em termos afetivos. Com isso, a filha se ressentiu e passou a agredir o irmão, pelo possível sentimento de "perda" da mãe. O pai, com o objetivo de suprir essa distância, aproximou-se da filha. E assim a família se configurou: a mãe se mantinha mais próxima do filho - de maneira superenvolvida, caracterizada por superproteção ao coitadinho, por ter sido sempre doentinho (gripes constantes), o que no parecer da psicoterapeuta o infantilizava e fragilizava emocionalmente ainda mais - e o pai tornou-se mais próximo da filha, estabelecendo assim uma aliança entre ambos (Minuchin, 1995).

No entanto, diante do processo terapêutico, terapeuta e pais julgaram pertinentes a flexibilização e a abertura das fronteiras por parte da mãe para que o pai conseguisse avançar e se tornar mais próximo do filho, inclusive em termos de poder e autoridade, já que a mãe era mais atuante nesse sentido, desautorizando e desqualificando muitas vezes o exercício da autoridade do pai, que complementava essa atitude submetendo-se, tornando-se periférico emocionalmente em relação aos filhos (Bustos, 1990; Minuchin, 1995). Dessa forma, a mãe se disponibilizaria mais para uma relação de maior proximidade afetiva também com a filha e os filhos poderiam vivenciar a liderança masculina.

Foi necessário, entretanto, ampliar as narrativas do casal no sentido de perceberem o padrão complementar que permeava a relação quanto ao exercício dos papéis de gênero, pois a esposa sempre havia exercido o poder primário em relação à família, fosse quanto aos aspectos financeiro, afetivo, educação dos filhos ou decisões importantes. Esse poder era complementado pela passividade do esposo, que se mantinha emocionalmente periférico, e freqüentemente era desqualificado e desconfirmado pela esposa, já que o julgava como "um fraco".

Em um processo colaborativo entre terapeuta e família, especialmente do casal, as narrativas foram sendo ampliadas e, assim, novos significados foram sendo construídos em torno das histórias dominantes. Nessa família imperava a crença de que as mulheres é que eram bonitas, inteligentes, bem sucedidas, elas é que "brilhavam". Bruno percebeu que era a mãe que tinha poder e brilho, pois era bonita, falante, bem-sucedida profissionalmente, destacava-se em entrevistas concedidas aos jornais e televisão. Sua irmã era também bonita, extrovertida, querida por toda a família e tinha lindos cabelos longos, que Bruno não se cansava de imitar com uma fralda na cabeça. Nas sessões psicodramáticas, o uso freqüente de uma peruca de cabelos longos expressava a sua admiração.

Esse padrão interacional de poder e brilho feminino também se revelou na dinâmica familiar dos avós maternos de Bruno, o que mobilizou na terapeuta o desejo de convidá-los a participar de alguns encontros. Houve concordância dos pais de Bruno, já que os avós mantinham uma relação bem próxima e freqüente com o neto, parecendo exercer significativa influência no que tangia ao seu desenvolvimento em geral. Após dois encontros, o avô se mobilizou no sentido de aproximar-se mais do neto e, com isso, contribuir com o desempenho de papéis e liderança masculinos; coube à avó favorecer esse espaço, visto que também mantinha uma relação de superenvolvimento com o neto e 
percebeu a importância de rever sua postura desqualificadora no que tangia aos homens.

A ressignificação do papel dos homens na família, especialmente de Bruno e de seu pai, foi um trabalho de grande significância, embora difícil e lento, pois exigiu uma real reconstrução para além das aparências e do dito.

Bruno começou a vivenciar uma nova organização familiar e novos significados quanto à aceitação ao respeito pelos homens e essa experiência começou a ser expressa nas cenas psicodramáticas e nos desenhos, nos quais Bruno e seu pai começaram emergir.

O pai passou a investir na relação com Bruno; tornaram-se cúmplices no desempenho de alguns papéis - ditos por eles como masculinos - como jogar bola, pescar, soltar pipa etc. Vieram para terapia juntos, em algumas sessões, e Bruno veio vestido com a roupa do seu time de futebol e com a bola que havia ganhado de seu pai.

No entanto, Bruno revelava que o sentimento de não se sentir aceito como menino ainda era forte, 0 que se evidenciou em uma sessão com a mãe, na qual Bruno dramatizou uma cena em que ele era uma "cachorrinha": aproximou-se da mãe, dizendo: "quero ser sua cachorrinha fofa.... cuida de mim". Nas cenas psicodramáticas, Bruno expressava suas percepções de que a mãe gostava somente de menina, porque menino é chato e chorão. E assim, na sessão com a mãe, ele se tornou uma cachorrinha fofa para que a mãe cuidasse dele.

Nas sessões lúdicas individuais, normalmente nas dramatizações, Bruno continuava a revelar seu mundo interno feminino - expresso na sua caracterização e desempenho de papéis femininos bem como nos desenhos - sempre acompanhado da peruca de cabelos longos que imitava o cabelo longo da irmã.

Em casa, segundo relato dos pais, Bruno ainda demonstrava interesse, se bem que com menor intensidade, pelas bonecas, tiaras, e continuava a imitar os cabelos longos da irmã com a fralda na cabeça, usava os sapatos de salto da mãe, e ainda apresentava trejeitos com as mãos e a fala infantilizada.

Ele queria ser igual à irmã para sentir-se aceito,

182 já que ela era amada por todos. Bruno estava fusionado emocionalmente com ela. Falava às vezes como se estivesse no papel dela (exemplo: eu sou a bruxa e depois reparava, ela é a bruxa). Nas sessões em que a irmã participou, ficou evidente a sua submissão. Ela determinava as brincadeiras: Bruno se submetia, mesmo quando não concordava.

A terapeuta investia cada vez mais no processo de fortalecimento emocional de Bruno, para que se sentisse aceito como ele era, e buscava promover na família, por intermédio do pai, uma maior liderança masculina.

Com o intuito de favorecer a expressão de sentimentos, a psicoterapeuta sugeriu a Bruno que trouxesse alguma roupa ou acessório da irmã para a sessão, caso ele quisesse, já que gostava muito das coisas dela. Na sessão seguinte, entrou feliz, trazendo um vestido dela. A princípio o deixou de lado, depois, fez duas tentativas de vesti-lo, pareceu ansioso e angustiado, suspirou e disse: "Ainda não tenho certeza se quero ser menina". Não quis se expressar sobre isso verbalmente, mas deixou de lado o vestido, que, embora tenha ficado na sala psicoterápica por meses, não mais chamou a atenção de Bruno. No entanto, seus sentimentos a respeito da irmã oscilavam nas cenas dramáticas entre admiração e raiva, simbolizados pela princesa e a bruxa.

Bermúdez (1997), em relação à criança, diferencia a etapa dos comentários, que é feita com os adultos. Quanto menor for a criança, o comentário verbal sobre o ocorrido é, geralmente, dispensável e, às vezes, contraproducente, já que na criança a apreensão se dá de uma maneira mais global e estrutural, não havendo necessidade de leituras ou traduções, que poderão inibir a espontaneidade em cenas futuras. O próprio atuar e os assinalamentos feitos pelo terapeuta na cena já são terapêuticos.

\section{Período intermediário}

Durante o processo, o casal entrou em crise conjugal e foi encaminhado para terapia de casal com outra profissional, já que pareceu interessante uma outra opinião, visto que, nesse caso específico, a terapeuta não estava fazendo terapia familiar e nem de casal, mas encontros familiares e de casal. Ao término da terapia de casal, a esposa continuou na 
modalidade individual, o que foi de grande auxílio para a terapia do filho.

Em uma sessão com a irmã, durante a dramatização de uma cena em que a irmã desempenhava o papel de rainha e Bruno de rei (agora já aceitava desempenhar papéis masculinos, o que não fazia anteriormente), e enquanto aguardavam o nascimento do filho que esperavam, discutiam sobre o sexo e nome do bebê. A rainha (irmã) queria que fosse uma menina, o rei (Bruno) queria que fosse um menino e que fosse chamado Bruno (começou a aceitar-se como menino, porque além de querer que o filho fosse menino, queria colocar seu nome). A rainha não concordou. O rei foi até a bola de cristal e disse que seriam gêmeos, uma menina e um menino. Eassim se sucedeu. Bruno, pela primeira vez, discordou de sua irmã e lutou pelo nascimento de um menino que teria seu nome. Finalmente, Bruno nasceu como menino e a partir de então, gradativamente, foi se diferenciando emocionalmente da irmã.

Já se sentia um menino, embora ainda precisasse do cabelão da irmã para se apoiar; não se sentia totalmente aceito, estava em um período de transição. Porém, estava mais seguro, a fala era menos infantilizada; em casa, a freqüência pela busca das coisas da irmã tinha se minimizado e a família se configurou com todos os componentes. Essa configuração é retratada num desenho da família que Bruno pede para fazer e nos comentários que faz a respeito.

Objetivando continuar favorecendo o desenvolvimento psicológico de Bruno nessa fase do processo terapêutico, na qual o menino já estava vinculado à terapeuta e demonstrando sentir-se aceito por ela, pais e terapeuta concordaram que seria de grande contribuição Bruno vivenciar trocas intersubjetivas com meninos de sua faixa etária, por intermédio de uma terapia grupal. O grupo era de caráter aberto, ou seja, no transcorrer do processo poderia tanto receber novos componentes como perdê-los. Além do critério da idade e do gênero, também foram escolhidos meninos cujas caracte-rísticas pudessem ser complementares ou mesmo simétricas, para que as crianças pudessem compartilhar e vivenciar diferentes experiências num clima de acolhimento e aceitação
(Marchi Costa, 2003). De início, comparado aos demais, que eram extrovertidos, briguentos, medrosos etc., evidenciou-se também a fragilidade emocional de Bruno, suas inseguranças mediante algumas situações que naturalmente emergiram no grupo e que o desafiavam. Essas características se complementaram e contribuíram para o desenvolvimento emocional de Bruno, na medida em que os companheiros tornaram-se fonte de desafios e modelos.

Gradativamente, nas ações dramáticas e em outros jogos lúdicos, Bruno passou de expectador ou auxiliar, ou seja, posições mais protegidas, para uma posição mais ativa, confrontadora. Por exemplo, em uma cena onde metade do grupo representaria o personagem Zorro e a outra os bandidos, Bruno ficava mais na coordenação, como alguém que auxiliava ou ficava de juiz, para depois, aos poucos, passar a ser também o Zorro e, com sua espada, que a princípio recuava diante do ataque do bandido, foi se fortalecendo e conseguindo confrontar e avançar no seu papel de Zorro. Começou, assim, a ter contato com suas reais potencialidades e, sentindo que estava sendo aceito por todos, foi se firmando, escolhendo desempenhar cada vez mais papéis de personagens masculinos. $O$ grupo foi de grande auxílio no seu desenvolvimento psicológico.

\section{Período final}

Bruno demonstrou estar bem integrado no grupo terapêutico, desempenhava papéis masculinos com segurança e, de acordo com o relato dos pais, isso também estava ocorrendo na escola com o grupo de meninos. Em casa, assumiu seus brinquedos, seu quarto, suas roupas, não se interessava mais pelas coisas da irmã. Ganhou um cachorrinho e designou-se como o pai, exercendo o papel de seu cuidador.

Bruno diferenciou-se psicologicamente da irmã, ganhou seu próprio espaço, não necessitava mais ser menina para sentir-se aceito e amado. Definiu-se como pessoa e quanto à sua identidade de gênero. Se desenhou como menino, e sem a peruca, e com características e sentimentos relativos ao gênero masculino. Se desenhou ao lado de sua irmã deixando a ela seu longo cabelo e adornos femininos. 
A catarse de integração está incluída no processo terapêutico e constitui o ápice de um caminho, no qual, gradativamente, ocorre a integração sistemática dos vários conteúdos que vão sendo trabalhados e/ou vivenciados pela criança. Para Moreno (1975), esse é o fenômeno que dá o verdadeiro sentido (valor) terapêutico ao psicodrama. Por intermédio da ação dramática, o indivíduo torna-se inteiro, completando alguma etapa de seu processo de identidade.

Os pais julgavam que Bruno estava pronto para deixar a terapia e a psicoterapeuta concordou e propôs follow up no ano seguinte. Bruno se desvinculou do grupo gradativamente, viajou por dez dias, e quando retornou fez uma última sessão individualmente, na qual pediu para desenhar as estórias do conflito das cores vermelha e azul (depois nomeadas como a irmã e a mãe, respectivamente). Ele, como o anjinho verde, chegou e auxiliou na reconciliação de ambas. Depois, chegou a cor azul (pai) e pulou no meio e todas as cores juntas, integradas e em harmonia, formaram um lindo quadro.

Bruno emergiu como conciliador dos conflitos entre a mãe e a sua irmã. Apresentou-se como o anjinho, não precisava mais ser "anjinha", e o pai, que anteriormente não aparecia em suas fantasias e que era rejeitado, agora também fazia parte da família. O quadro familiar se configurou numa integração harmoniosa. Bruno se integrou e integrou-se à sua família.

\section{Follow up}

Após 12 e 24 meses do término da terapia, realizou-se encontro com os pais, que relataram que Bruno continuava lutando pelo seu espaço; na escola, estava bem integrado ao grupo masculino e estava participando do time de basquete. Estava um verdadeiro moleque.

No terceiro encontro, realizado no ano seguinte e três anos após o término do processo, o reencontro se deu com Bruno. Ele estava para completar nove anos. Quando chegou foi logo falando que trouxera alguns desenhos para mostrar à terapeuta, já que continuava gostando de desenhar. Na sala de brinquedos olhou por tudo, suspirou e disse: "Quantas saudades, saudades da sala, dos colegas do grupo, das

184 brincadeiras, quantas coisas fizemos aqui..., as roupas (fantasias)....' Comentou sobre sua escola, seus amigos, o time de basquete, as meninas que não paravam de ligar na sua casa, e também sobre a irmã, que continuava chata e implicando com ele. Disse ainda que a mãe continuava mandando e implicando muito com o seu pai, e complementou dizendo: "essas mulheres são muito autoritárias", mas que ele estava muito bem.

A psicoterapeuta perguntou-lhe o que gostaria de fazer nesse reencontro e ele disse que gostaria de fazer o que melhor sabia fazer, ou seja, desenhar, e "quando eu crescer quero ser um desenhista de primeira classe. Além de casar, é claro, quero ser um marido também, só que não quero ter filhos, porque eles fazem muita bagunça". E assim, escolheu o tema e começou a desenhar, "quando eu for um adolescente".

Observa-se que Bruno se projeta no futuro com características e desejos típicos de um adolescente: namorar, passear, jogar etc. Já que gostava de desenhar, a terapeuta pediu-Ihe para desenhar sua família, visando possibilitar ampliações a respeito de como estava vivenciando essa relação, bem como quanto aos demais membros entre si e com Bruno. Fez o desenho e ratificou os conflitos que tinha com sua irmã ao lhe atribuir alguns qualificativos negativos (burra, dentuça etc.), pois sentia que ela era autoritária como sua mãe e implicava muito com ele. Quanto ao pai, disse que tinha bastante dinheiro e que trabalhava muito para ganhá-lo, porque a mãe gostava de dinheiro. A conversa em torno dessas questões foi ampliada, no entanto, Bruno não trouxe nenhum vestígio do transtorno de identidade de gênero. Mostrou-se um menino feliz, seguro e bem integrado socialmente. Suas projeções para o futuro expressaram, na base, o gênero masculino e seus respectivos papéis.

\section{Considerações Finais}

A terapeuta apoiou-se na visão sistêmica novo-paradigmática em que fica implícita uma visão construtivista e construcionista social da realidade e ao mesmo tempo apoiou-se também em uma prática tradicional, o psicodrama, bem como em alguns autores representantes desse período. Nesse sentido se respalda nas epistemólogas Grandesso (2000b) e Vasconcellos (2004b), que salientam que o 
profissional deve se sentir livre para resgatar as teorias e as técnicas desenvolvidas em contextos de ciência tradicional, que agora estarão transformadas por seu novo olhar sobre elas.

Vale ressaltar também que, embora a terapeuta tenha iniciado esse estudo a partir de uma categoria diagnóstica nosológica: "Transtorno de Identidade de Gênero", para melhor situar o leitor, não se fixou nesse rótulo, e buscou compreender Bruno na sua singularidade.

A terapeuta optou por apostar em uma direção não essencialista, investiu na reconstrução de novos significados em torno da história de Bruno e de sua família. Pelas histórias narradas, em um processo de co-construção com todos os participantes do processo, hipotetizava que a negação, por parte de Bruno, de sua identidade, era de origem psicológica, e que havia sido construída no transcorrer de seu desenvolvido biopsicossocial, em um processo de co-construção com sua família. Bruno não se sentia aceito pelas pessoas do gênero feminino, especial-mente por sua mãe, que passava implícita e explicitamente sua rejeição pelo gênero masculino, ao passo que o gênero feminino era admirado e confirmado o tempo todo, especialmente quando se tratava de sua irmã que era vista como a "rainha do lar", com todos os qualificativos positivos. Bruno demonstrava o tempo todo querer ser a sua irmã, ou pelo menos ser igual a ela, pois, assim sendo, seria aceito e confirmado pela família. Passou a rejeitar tudo que se relacionava ao gênero masculino como forma de se sentir pertencendo a esse sistema.

Diante de ampliações de narrativas e da desconstrução do que era significado como problema, a família ressignificou sua relação e vínculo com o filho, o que possibilitou novas organizações em torno da dinâmica familiar, oportunizando que o menino também ressignificasse a sua importância e o seu lugar nessa família. Assim, resgatou a autoria de sua vida, diferenciou-se emocionalmente de sua irmã e aceitou sua identidade masculina, com conseqüente desempenho de papéis sociais a ela vinculados. O sofrimento em torno da narrativa dominante foi desconstruído e a identidade de gênero do menino foi reconstruída.

Não se sabe que tipo de opção sexual terá o adolescente/adulto Bruno, mas sabe-se que hoje o menino Bruno consegue ser amado como filho, irmão, neto, amigo etc. Conquistou o seu espaço e reencontrou-se consigo mesmo.

\section{Referências}

Anderson, H. (1997). Conversation, language, and possibilities: a postmodern approach to therapy. New York: Basic Books.

Bermúdez, J.G.R. (1970). Introdução ao psicodrama. São Paulo: Mestre Jou.

Bermúdez, J.G.R. (1997). Teoria y técnica psicodramatica. Buenos Aires: Paidós.

Bustos, D. (1990). Perigo, amor à vista: drama e psicodrama de casais. São Paulo: Aleph.

Costa, R.P. (1994). Os 11 sexos. São Paulo: Gente.

Freedman, J., \& Combs, G. (1996). Narrative therapy: the social construction of preferred realities. New York: W.W. Norton.

Grandesso, M.A. (2000a). Quem é a dona da história? In H.M. Cruz. Papai, mamãe, você... Eeu? Conversações terapêuticas em famílias com crianças (pp.101-122). São Paulo: Casa do Psicólogo.

Grandesso, M.A. (2000b). Sobre a reconstrução do significado: uma análise epistemológica e hermenêutica da prática clínica. São Paulo: Casa do Psicólogo.

Grúnspun, H. (1999). Crianças e adolescentes com transtornos psicológicos e do desenvolvimento. São Paulo: Atheneu.

Marchi Costa, M.I. (2003). A prática da psicoterapia infantil a partir do referencial teórico do psicodrama, Gestalt Terapia e abordagem centrada na pessoa, sob as óticas de Bermúdez, Ferrari, Oaklander e Axline. Dissertação de mestrado, Universidade Católica de Pernambuco, Recife.

Minuchin, S., \& Nichols, M. (1995). A Cura da família. Porto. Alegre: Artes Médicas.

Moreno, J.L. (1975). Psicodrama. São Paulo: Cultrix.

Organização Mundial de Saúde. (1993). Classificação de transtornos mentais e de comportamento da CID-10: descrições clínicas e diretrizes diagnósticas. Porto Alegre: Artes Médicas.

Vasconcellos, M.J.E. (2004a). Colóquio inicial: conversações sobre conversações transformadoras. In Anais do sexto Congresso Brasileiro de Terapia Familiar, Florianópolis, $\mathrm{SC}$.

Vasconcellos, M.J.E. (2004b). Implicações do pensamento sistêmico novo-paradigmático: a questão da dicotomia "terapia familiar sistêmica"/"terapia familiar narrativista". Nova Perspectiva Sistêmica, 12 (24), 7-13.

White, M., \& Epston, D. (1990). Narrative means to therapeutic ends. New York: W.W. Norton.

Recebido para publicação em 22 de setembro de 2004 e aceito em 18 abril de 2005. 
